\title{
ACTIVE VERSUS PASSIVE INVESTING - AN ANALYSIS OF UK EQUITY MARKETS, 1991-2005
}

\author{
Barnes, E. ${ }^{1}$ and Scott, M. \\ University College Cork, Ireland.
}

\begin{abstract}
This study examines the pattern of active versus passive trading in UK equities over the period 1991-2005. We describe a metric to analyse trading activity and volumes in the UK FTSE350 and AIM markets, with emphasis on industrial and size-based effects. $^{12,1}$ Our findings indicate that active stock picking has been consistently declining in the UK market over the period studied for all markets, size quintiles and in virtually every industrial sector. Moreover, trading patterns reveal a pronounced size effect with significantly less stock picking in larger capitalisation stocks vis-à-vis smaller stocks. Patterns of investment in the AIM suggest an increase in index trading over time but higher overall levels of stock picking relative to the FTSE350 list.
\end{abstract}

EFM Classification: 350,370

\footnotetext{
1 Address for Correspondence: Dr Edel Barnes, National University of Ireland, Cork, O'Rahilly
} Building, UCC, College Road, Cork, Ireland. Tel: +353 21 4902839. Email: e.barnes@ucc.ie. 


\section{INTRODUCTION}

Theories of efficient markets, standard paradigms of academic and empirical finance, have clear implications for asset combination and diversification decisions. If markets are efficient and operate well, prices should reflect all available information regarding firms' financial position and future prospects and it should not be possible to beat the market other than by chance. Investors should only be able to earn abnormal returns by having access to private firm information, superior forecasting ability or through chance. In consequence, rather than incur the significant private costs of research to obtain proprietary information, investors should be as well off investing (passively) in a market index which includes a broad range of different securities. With this approach, the volume of trade in any particular stock should reflect the weight of that firm in the market portfolio/index, and market weighting should explain fully the variation in volume of trade.

However in a climate of low interest rates, as investors seek superior returns one might expect significant active investment as distinct from passive investment. This leads to an upsurge in the use of skill and research on the part of professional investors to identify mispriced securities and trade on that mispricing, a process which is costly and which offers no guarantee that benefits will outweigh the very substantial costs of information acquisition and trading. Carhart (1997) among others documents the magnitude of active vis-à-vis passive trading costs and notes that, in terms of net returns, actively managed investment funds have tended to under-perform their passively managed counterparts. ${ }^{2}$ If the benefits of active fund management consistently fail to outweigh the costs passive investment is surely more constructive for investors. 
Despite extensive empirical evidence on patterns in, and costs of active vis-à-vis passive trading, evidence largely relates to US markets and comparatively little research has been conducted into patterns of trading in UK markets. Given the global significance of the London market, we consider that an in-depth examination of active vis-à-vis passive trading patterns for the UK is merited, and that such evidence would represent an interesting increment to the body of literature at this point. The purpose of this study is to examine the pattern of active versus passive trading in UK equities over the period 1991-2005 inclusive. Drawing on the two fund separation theorem (Lo and Wang, 2000; Bhattacharya and Galpin, 2005) we describe a metric to analyse trading activity and volumes in the UK FTSE350 and AIM markets, with emphasis on industrial and size-based effects. ${ }^{12,1}$

Our findings indicate that active stock picking has been consistently declining in the UK market over the period studied for all markets, size quintiles and in virtually every industrial sector, which evidence is consistent with patterns of trading documented for the US and some other markets. Our findings in respect of UK trading patterns reveal a pronounced size effect with significantly less stock picking in larger capitalisation stocks vis-à-vis smaller stocks. Patterns of investment in the AIM suggest and increase in index trading over time but higher overall levels of stock picking relative to the FTSE350 list.

Our paper is structured as follows. The next section presents an analysis of the theoretical motivations for and empirical evidence pertaining to stock and index trading and is followed by section three which describes our sample and the methodology we apply. The fourth section outlines the results of our analysis together with a discussion of those results and their consistence with the extant 
literature. In our final section we identify some limitations of our analysis together with some avenues for further study, and conclude.

\section{LITERATURE REVIEW}

Carhart (1997) among others documents the magnitude of active vis-à-vis passive trading costs and notes that actively managed investment funds have tended to be substantially more costly for investors reducing net investment returns. ${ }^{2}$ This author examines persistence in fund performance for equity mutual funds in the US for the period 1962-93 and finds that persistence is almost completely explained by common stock factors and investment expenses. Over the long term he concludes that there is no significant momentum effect (the benefit of continuing to hold last year's winning stocks, identified by Fama and French, 1996) and that expense ratios, transactions costs and turnover are negatively related to mutual fund performance. ${ }^{4}$ Essentially his findings are not supportive of the existence of significant stock selectivity skills among mutual fund managers for the period of his study.

Jensen (1968) identified stock selection ability and diversification/ risk minimisation as separate fund management responsibilities and based on the Sharpe/Lintner CAPM model, examined fund managers' 'predictive ability' in an analysis of US fund managers over the period 1945-64, the regression intercept term or alpha representing stock selection ability. ${ }^{9}$ His findings indicate that over the sample period the mean fund was unable to generate sufficient returns to cover trading costs and would not have outperformed a passive 'buy and hold' investment approach.

In light of the historically poor returns to active fund management, Gruber (1996) queries why investors choose to buy actively managed funds on finding that 
active management adds value but that fund charges exceed this value added. ${ }^{8}$ Wermers (2000) re-examines the value-added by mutual fund managers based on hypothetical stocks-only funds and concludes that while such funds outperformed the CRSP on average for his study period with higher turnover funds doing relatively better, the net effect of transactions costs and non-stock holdings resulted in his sample funds underperforming a passive indexing approach by $1 \%$ per annum on average. ${ }^{17}$ Grinblatt and Titman $(1989,1993)$ report mutual fund out performance consistent with Wermers' (2000) findings but their findings with respect to the substantial drag on net returns of actively managed fund transactions costs are consistent with Wermers. ${ }^{6}$ A useful comment on the active versus passive debate is provided in Malkiel (2003). ${ }^{13}$

In summary the body of literature seems to indicate that active management does not justify the fees typically charged for this service. If the benefits of active fund management are consistently negligible or even negative, passive investment is surely more constructive for investors and one would expect to observe indexing as the dominant investment philosophy if markets truly are efficient. To date the main body of literature relating to the prevalence of active versus passive investors is not well developed. Such literature as exists regarding persistence in performance, efficient markets and mutual fund performance have been carried out in the US and typically on US data.

A Bhattacharya and Galpin (2005) paper incorporates an important contribution to the debate by developing a metric to measure indexing. ${ }^{1}$ These authors collected share volume and shares outstanding data from CRSP for NYSE, AMEX and NASDAQ listed stocks for the period July 1962 - December 2004, and for 43 other markets around the world from DataStream for the period January 1995 - July 2004, 
in order to conduct cross sectional monthly regressions. The 43 non-US markets are classified as emerging markets (22) and developed markets (21). A key finding is that there appears to be more stock picking in emerging markets (maximum 63\%) vis-àvis developed markets (maximum 45\%), which result is intuitive given the greater coverage of stocks and sounder institutional arrangements in developed markets. Important exceptions are Germany which appears to have more stock picking than one would expect for a developed country (maximum 71\%) and Russia which appears to have surprisingly little stock picking (maximum 35\%). Notably the maximum proportion of stock picking was lowest in the US with 29\% and greatest in China (maximum $80 \%$ ). A further key finding is that stock picking appears to be declining systematically around the world, with this decline being most pronounced in emerging markets although the US data reveal a decline to a low of $24 \%$ in the 2000 s compared to an average level of stock picking in the late 1960 s of $60 \%$.

When these authors examine their US data more minutely some further trends and patterns are apparent. Consistent with the practicalities of indexing, the practice is significantly more extensive for $\mathrm{S}+\mathrm{P} 500$ vis-à-vis non-S+P 500 stocks although indexing appears to be gaining in popularity for both categories of shares. Share turnover is also relatively greater for the larger non-S+P 500 shares. At all points examined, indexing seems to be greater for NYSE-listed vis-à-vis AMEX-listed stocks and indexing in the NASDAQ resembled that in the AMEX in the 1980s but more closely resembled trading in the NYSE post-2000 at which time stock picking in NASDAQ-traded stocks started to decline noticeably. There has been a consistent decline in stock-picking over time in all three markets however, and an apparent size effect as there seems to be greater indexing in larger stocks across all the US markets examined. Furthermore, partitioning by age, the authors find less stock picking in 
older stocks vis-à-vis young firm stocks. Again stock-picking is observed to be in decline across firms of all ages and across the 10 Fama and French (1997) industry classifications, although the maximum proportion of stock picking is higher in telecommunications which the authors describe as 'exciting' relative to 'boring' utilities.

Bhattacharya and Galpin hypothesise that analysts have expertise in identifying mispriced stocks and pick stocks that others should pick later. ${ }^{1}$ Using IBES data on analyst following they find, inconsistent with their priors, that investors conduct more stock picking in stocks that analysts do not pick and hypothesise that this seems plausible if by undertaking and acting on their own research analysts consequently reduce the payoff to stock picking on one's own account. Again stock picking appears to be in decline across both analyst-followed and non-followed stocks with indexing being more pronounced in stocks followed by greater numbers of analysts.

In light of findings that stock picking is declining across all markets and subdivisions of the data studied, Bhattacharya et al. question the 'long-run steady state fraction of stock-pickers' and develop a model based on firm specific risks and payoffs, trading costs and the market price of risk (the market Sharpe ratio) which is then applied to US data for the period 1964-2004. ${ }^{1}$ Their findings suggest that firmspecific risk has been increasing over time and that stock-picking has declined in tandem. At a long-run estimate of a 'net benefit to stock-picking' measure, they estimate a steady state maximum proportion of stock-picking of approximately $11 \%$, at which level the authors predict that stock-picking will eventually settle in the US. The United Kingdom is one of the developed markets examined by Bhattacharya et al. (2005). ${ }^{1}$ In terms of world rankings of stock picking, the UK ranks $9^{\text {th }}\left(21^{\text {st }}\right)$ over the period 1995-99 (2000-04) respectively with a maximum proportion of stock picking 
of $47 \%(51 \%)$ respectively. While the estimated differential is not large, it is nevertheless interesting that the UK is one of very few markets in which the extent of indexing actually declined over that period, in consequence of which we consider that a fuller exploration of trading patterns in the UK might yield noteworthy findings. We also perceive the potential to examine more closely the role of industry, and of firm age or establishment in light of the existence since 1995 of trading in the UK Alternative Investment Market (AIM). It is to this analysis that we now turn.

\section{DATA AND METHODOLOGY}

The main objective of our analysis here is to investigate, illustrate and explain any variation in the patterns of active vis-à-vis passive equity trading over the period 1991-2005 inclusive for the FTSE350 and AIM markets, and specifically to explore any trends in stock-picking versus indexing for the period. We seek to ascertain the extent to which trading volume is explained by stock picking in the UK, whether there is a size and/or industry effect in such trading and whether patterns that apply to the FTSE350 main list are also apparent in AIM trading. Our methodological approach is based on that of Bhattacharya and Galpin (2005). ${ }^{1}$ Their metric draws on insights of Lo and Wang (2000) who in turn base their theoretical discussion on Tobin's (1958) two-fund separation theorem. ${ }^{12,16}$ Briefly, if the two-fund separation theorem holds and everybody in the world indexes between a risk-free asset and a value-weighted proxy for the market portfolio, with no price changes between trades, share turnover for each stock defined as share trading volume scaled by number of shares outstanding, should be identical for all stocks in the portfolio. Essentially (dollar) trading volume in any stock $\mathrm{i}$ should be entirely explained by the market capitalization of that stock. Regressing share trading volume on number of shares 
outstanding for each stock would yield a beta of 1 and an $\mathrm{R}^{2}=1$ if all investment in the market is indexing. To the extent that $\mathrm{R}^{2}$ differs from 1 , there has been a deviation from indexing which could reflect either stock picking or alternative investment strategies such as indexing to an alternative market index, hedging derivative positions etc. Thus $\mathrm{R}^{2}$ in the following regression

$$
\operatorname{Ln}(\mathrm{VOL})_{i}=\alpha+\beta_{i} \operatorname{Ln}(\mathrm{NOSH})_{i}+\varepsilon_{i}
$$

represents the proportion/extent of indexing in a given market and $\left(1-\mathrm{R}^{2}\right)$ represents the maximum proportion of investment trading that can be explained by stock-picking. VOL is the monthly $£$ volume of shares traded scaled by market capitalisation, NOSH is the $£$ value of shares outstanding for each stock at the end of that trading month (adjusted for closely held shares). The intercept term $\alpha$ represents the log of turnover, and the regression coefficient $\beta$ describes the relation between trading volume and shares outstanding. The error term may be interpreted as a measure of abnormal volume at the firm-level. It is important to note that our stock-picking metric represents the maximum volume of shares traded that can be explained by stock picking, as it implicitly assumes that investors are indexers or not. $\left(\mathrm{R}^{2}\right.$ will differ from 1 if agents either pick individual stocks in which to invest or alternatively index to tailored portfolios such as hedge funds of funds or exchange traded funds, which latter have enjoyed increasing popularity in recent times.) The metric does not distinguish between stock picking and the activities of hedge funds and funds of funds for example. However we consider that its appeal lies in its simplicity, understandability and ease of computation, requiring neither a highly quantitative background nor appreciation of complex statistics for its comprehension. It yields a 
measure which by default describes the extent of indexing in the market and in consequence allows us to infer trends in approaches to investment over the period studied.

Our analysis of the nature of stock trading activity in the UK centres on the FTSE350 list which we consider offers a happy medium between the small number of stocks that constitute the FT100 main list and the larger FTALLSH index which would present considerable data challenges. For comparative purposes we also analyse trading patterns for the newer AIM market which commenced trading in June, 1995 and which offers smaller firms an opportunity to access capital without the rigorous listing requirements of a full listing. Companies that list and enjoy share trading on the AIM are typically smaller and younger than those on the main list. For each month over the period January 1991 - December 2005 we obtain (aggregate) trading volume and NOSH data (at month end) for every firm in our sample and conduct monthly regressions as in equation [1] above. To be included in our sample a share must be on ordinary common share and be listed in its own country. There was some variation in the constituents of the 350 list, some companies disappearing over time and others not having obtained a listing until after the sample period commenced. We select at random 210 companies on which to base our analysis, representing $60 \%$ of the constituent firms at any point in time. These data were obtained from DataStream. For our size analysis we partition our sample companies into quintiles according to market capitalisation for every month, quintile 1 (5) containing the largest (smallest) stocks by market value respectively and we conduct difference of means tests on $\left(1-\mathrm{R}^{2}\right)$ measures to assess any size effect. For our industry analysis we base our analysis on the DataStream industry classifications (25). Some categories had fewer than 4 companies so we reclassified these firms under the 
'other' classification, resulting in 17 distinct groupings for the FTSE350 sample. Codes ranging from 1-17 inclusive were accorded to each firm to facilitate our differentiation by industry. We do not seek to explore the existence of a size or industry effect in our AIM sample for which just 10 years of data were available January 1996 - December 2005 and we omit the period 1 June 1995 - 31 December 1995 to allow for market settling in this introductory trading period. Our metrics of key interest are $\mathrm{R}^{2}$ and by extension $\left(1-\mathrm{R}^{2}\right)$ which represent the proportion off indexing (maximum proportion of stock picking) respectively, though the intercept term which represents log of turnover also provides some useful hints about the absolute volume of trade in the various data sets. We conduct the Ryan-Joiner test of normality and the Durbin-Watson test for autocorrelation and find no non-stationarity in our data. Skewness is predictably a feature as turnover is necessarily bounded by 0 which induces positive skewness. We employ the White test for heteroskedasticity, again this is not a feature of our data though it might plausibly have been present in such time-series data. In consequence we utilise OLS and base our tests of significance on parametric P-values and (Fischer) F-statistics, and our t-statistics are of the 2 -sided test of the null $\beta=1$.

As the error term in our cross-sectional regression represents a measure of abnormal volume at the firm level, we obtain monthly returns for each firm over the sample period from DataStream and relate them to this abnormal volume measure as follows:

$$
R_{i t}=\alpha+\beta(A V o l)_{i t}+\varepsilon_{i}
$$

where $\mathrm{R}_{\mathrm{it}}$ is the firm-level return for firm $\mathrm{i}$ in month $\mathrm{t}, \mathrm{AVol}_{\mathrm{it}}$ is abnormal volume from equation [1], $\alpha, \beta$ are regression coefficients and $e_{i}$ the error term, to explore 
whether abnormal volume might have explanatory or predictive power for returns. Table I below describes our data for both FTSE350 and AIM companies at 31 December 2005, the end point of our sample period.

\section{Table 1 about here}

Clearly and unsurprisingly the mean FTSE350 firm is larger, enjoys significantly greater aggregate monthly trading volume and has significantly greater numbers of shares outstanding than its AIM counterpart. There is no minimum market capitalisation requirement for an AIM listing and the FTSE350 market has substantially greater market liquidity.

\section{RESULTS}

Table 2 presents the results of applying equation [1] above to our FTSE350 data, where $\mathrm{R}^{2}\left(1-\mathrm{R}^{2}\right)$ represent the proportions of indexing (maximum stock-picking) respectively. Our sample period pre(post)-dates that of Bhattacharya and Galpin (2005) by some 4 (1) years. ${ }^{1}$ We are unclear about the specific stocks that constitute their UK list so that comparisons are somewhat problematic other than in general import and theme.

\section{Table 2 about here}

Throughout our beta value is greater than 1 at the $1 \%$ level so that while volume was approximately linear in NOSH an increase in shares outstanding resulted in a greater percentage change in the volume of trading with this effect being more pronounced through time. Our F-statistics suggest that the regression is highly significant in every

period studied. $\mathrm{R}^{2}$, the measure of proportionate indexing shows a clear trend 
upwards and there is a corresponding decline in the extent of stock-picking and other non-indexing trades, which accords both with our priors and with evidence for the US and other markets documented by Bhattacharya and Galpin (2005). ${ }^{1}$ Our mean (maximum proportion of) stock picking at 31\% appears lower than the median reported by Bhattacharya et al. of $49 \%$ and we report a systematic decline in stock picking over time while Bhattacharya reports a slight increase in stock-picking for the later years in his sample (to $51 \%$ for the $2000-4$ period). ${ }^{1}$ Our difference of means tests indicate that the level of indexing was significantly lower in 1991 relative to both the average over 1991-2005 (t-stat 21.62, p-value 0.000) and to the level recorded for 2005 at the end of our sample period (t-stat 24.61, p-value 0.000). These findings are consistent with those of Bhattacharya et al. (2005) who document a decline from $60 \%$ to $24 \%$ over the period 1960 s-2000s for US markets. ${ }^{1}$ Figure 1 below highlights this pronounced decline in stock picking over time for the FTSE350:

\section{Figure 1 about here}

Table 3 below presents the findings of our size analysis for quintiles of the FTSE350 where quintile 1 (5) represents the largest (smallest) stocks by market capitalisation respectively and metrics are mean values for the 1991-2005 period. For all quintiles the model statistics indicate significance at the $1 \%$ level and there is a clear size effect evident in the data with indexing being significantly greater in larger stocks vis-à-vis smaller ones. Difference of means tests confirm this size effect, (t-stat 22.05; p-value 0.000), and also that within each quintile there has been a systematic and significant decline in stock picking over time, a pattern that is evident in Figure 2 below.

\section{Figure 2 about here}




\section{Table 3 about here}

These findings are consistent with Bhattacharya and Galpin (2005), who document a similar size effect and time trend for US stocks. ${ }^{1}$ We are unsurprised with these data, stock picking tends to be more prevalent in markets where there is less public disclosure of stock-specific information and analyst following (and consequent publication of price-sensitive information) is greater for larger capitalisation stocks. For our industry analysis we partition our FTSE350 stocks into the DataStream classifications as discussed in Section Three above. The mean number of companies per industry was 12.35 with a maximum (minimum) of 19 (4) respectively. Table 4 presents our findings with respect to these groupings for the period 1991-2005:

\section{Table 4 about here}

There is considerable variation in the relative dominance of each investment philosophy across industry type with stock picking in the Electrical and Utility (Chemical and Pharmaceutical) industries being significantly greater (less) than the mean. While not reported here, our $\left(1-\mathrm{R}^{2}\right)$ measures indicate a systematic decline in stock picking over the period studied for every industrial grouping. To an extent our findings are consistent with those of Bhattacharya and Galpin who report greater indexing in the 'boring' utility sector as do we, however we find no 'exciting' telecoms effect, stock picking in this UK sector having fallen over time rather than the reverse which appears to have been the US experience.

If analysts improve the information environment of the stocks they research and pick, thus reducing the benefits of stock picking, it seems intuitive that the returns to information gathering and in consequence stock picking will be greater in stocks that 
have less analyst following. In the UK stocks in the FTSE350 have widespread following but this is much less the case in AIM-listed stocks which tend to be smaller, younger, start-up enterprises without the trading history or visibility of larger stocks. Table 5 reports our indexing (non-indexing) metrics for AIM-listed stocks for the period 1996-2005 inclusive, the AIM having commenced trading only in June 1995.

\section{Table 5 about here}

In 1996, the first full year of trading in AIM-listed stocks thin trading would likely be a feature of the exchange and the concept of indexing substantially premature formal indexing essentially became possible only from 01/1999 when approximately 320 firms were listed though AIM firm numbers were 500 from 2001. For the period as a whole, mean indexing is increasing albeit 2000 saw somewhat of a resurgence of the stock picking practice, which effect is likely due to the popularity of hightechnology and start-up stocks at the time, a large number of which would have been listed on the AIM. Only towards the end of our sample period does volume traded approach linearity with shares outstanding, in the earlier years of the exchange's existence, volume traded fell substantially short of outstanding shares. When we compare indexing (non-indexing) in the FTSE350 with the AIM (for the period 19962005) our difference of means tests indicate that indexing was significantly greater (lower) in the FTSE350 (AIM) stocks overall and in each calendar year, and our intercepts suggest greater turnover in FTSE350 shares but more trading in larger AIM stocks vis-à-vis smaller ones. At the end of our sample period indexing in the FTSE350 averaged $79.5 \%$ compared with $45.8 \%$ for the AIM. From a practical perspective (and indexing is the practical manifestation or implementation of the tenets of modern portfolio theory) indexing is of course far easier for the FTSE350 
stocks and would not have been possible before 1999 for the AIM. However both groups indicate a systematic trend upwards in indexing at the expense of stockpicking, which is more pronounced in the AIM, possibly because stock picking started at a substantially greater level, also because the decline in stock picking for the FTSE350, for which we have a longer time series of data, pre-dates this comparative

period. It remains to be seen whether levels of stock-picking for these exchanges will converge over time or whether there is always likely to be somewhat less indexing in the AIM vis-à-vis the FTSE350, which pattern has been observed for the NASDAQ relative to the NYSE for the US market. There are substantial tax breaks available to investors that buy and hold AIM-listed stocks, which provide a disincentive to more active trading in individual shares. Figure 3 below depicts these trading patterns for UK markets for the period 1996-2005:

\section{Figure 3 about here}

In summary, we report here a significant decline in stock-picking for both FTSE350 and AIM markets over time, which results are robust to size and industry sector, and in general small capitalisation stocks are shown to attract greater stock picking activity than larger capitalisation stocks. While we do not undertake any systematic analysis of an abnormal trading volume association with firm returns, we identify this area as potentially yielding interesting research findings moving forward.

\section{SUMMARY}

In efficient markets asset prices fully reflect all available firm-specific information and it should not be possible to beat the market other than by chance. If asset prices do not reflect all relevant information, it may be possible to earn superior 
returns by undertaking research to identify value-relevant firm information and taking action thereon. The purpose of this study was to examine the pattern of active versus passive trading in UK equities over the period 1991-2005 inclusive. Our metric to analyse trading activity and volumes on the UK FTSE350 and AIM markets draws on the two fund separation theorem (Lo and Wang, 2000; Bhattacharya and Galpin, 2005), and we explore industrial and size-based effects. ${ }^{12,1}$ Our findings indicate that active stock picking has been consistently declining in the UK market over the period studied for all markets, size quintiles and in virtually every industrial sector, although the AIM did see a brief resurgence of stock picking around 2000-1 at the height of the dot-com investment bubble. Moreover, trading patterns in the larger capitalisation FTSE350 list reveal a pronounced size effect with significantly less stock picking in larger capitalisation stocks vis-à-vis smaller stocks. Patterns of investment in the AIM suggest an increase in index trading over time but higher overall levels of stock picking relative to the FTSE350. This is likely due to the shorter history of the AIM and the characteristics of stocks traded thereon; however it will be interesting to observe whether trading patterns converge with those of the FTSE350 as has been observed for the NASDAQ vis-à-vis the NYSE markets, when we have a longer time series of data for the AIM. Our results are not especially surprising and are largely consistent with those of Bhattacharya and Galpin (2005) although we do report a level of stock picking for our FTSE350 that is substantially less than that which BG report for their undefined UK market. ${ }^{1}$ If our constituent stocks are on average larger than theirs, taken in conjunction with our pronounced size effect there may be a resolution of the differential here. We fail to find any well-defined 'excitement/boredom' factor in patterns of industrial trading, though we report the greatest relative extent of 
indexing in the Chemical and Pharmaceutical sector which is characterised in the UK by relatively small numbers of large capitalisation stocks.

The evolution of the estimated stock picking impact over time is an issue which merits some consideration. The period covered by our study spans several cycles in the market from recession through recovery and expansion and back to recession from which a further recovery eventually materialised in the early years of this century. Over the period, many economic and geo-political events occurred which may well have influenced investor behaviour for which our statistics proxy. Throughout that period there has been a pronounced and consistent decline in active stock-picking at the expense of passive investment, and we remind ourselves that our stock-picking metric includes all non-indexing behaviour. Essentially and notwithstanding developments such as the introduction of ETFs and the increasing activity of hedge funds, active investment appears to be in decline. Whether this decline continues or whether stock picking will eventually settle at some 'long run steady state level' remains to be seen. Was this level, if it emerges, to be significantly lower than the mean level we report at the end of our sample, such a development would have serious implications for financial activity in The City and for a fund management industry which has exhibited unprecedented growth in the past decade.

We recognise the simplistic nature of the BG metric we compute in respect of stock picking in that it essentially measures all 'non-indexing' investment behaviour. ${ }^{1}$ An interesting avenue for further study involves a more granular exploration of the impact if any of Exchange Traded Funds on investors' decision choices and whether this relatively low-cost investment approach which amplifies the net returns differential between indexing vis-à-vis active investment has substantially hastened 
the observed decline in stock-picking. These are themes which we hope to pursue moving forward. 
Table I: Descriptive Statistics

\begin{tabular}{|c|c|c|c|c|}
\hline \multicolumn{2}{|l|}{ Market } & \multicolumn{2}{|l|}{ FTSE350 } & AIM \\
\hline \multicolumn{2}{|c|}{ No. of Companies } & \multicolumn{2}{|l|}{210} & 500 \\
\hline \multicolumn{2}{|l|}{ Mean MV £m } & \multicolumn{2}{|l|}{$6,778.5$} & 31.3 \\
\hline \multicolumn{2}{|c|}{ Mean Volume 000s } & \multicolumn{2}{|l|}{150.75} & 3.69 \\
\hline \multicolumn{2}{|c|}{ Mean NOSH 000s } & \multicolumn{2}{|l|}{1205.55} & 155.76 \\
\hline Variables & Ln(VO) & Ln(NOSH) & Ln(VO) & Ln(NOSH) \\
\hline No of obs. & 37800 & 37800 & 59760 & 59760 \\
\hline Mean & 10.251 & 12.814 & 5.762 & 10.451 \\
\hline Median & 10.246 & 12.777 & 5.929 & 10.360 \\
\hline SE (Mean) & 0.009 & 0.007 & 0.01 & 0.007 \\
\hline Std. Deviation & 1.605 & 1.264 & 2.539 & 1.53 \\
\hline Minimum & 1.569 & 8.509 & 2.302 & 2.303 \\
\hline Maximum & 16.56 & 18.04 & 14.17 & 17.52 \\
\hline Skewness & -0.02 & 0.26 & -0.31 & 0.01 \\
\hline Kurtosis & 2.96 & 3.09 & 2.88 & 3.17 \\
\hline Durbin-Watson & 1.87 & 1.91 & 1.89 & 1.88 \\
\hline Ryan-Joiner & 0.999 & 0.997 & 0.997 & 0.996 \\
\hline
\end{tabular}

$\mathrm{MV}=$ Market Capitalisation; Volume=aggregate volume of shares traded per month; $\mathrm{NOSH}=$ number of shares outstanding at end of calendar month, statistics presented are averages across all shares in each list respectively at 31 December, 2005. 
Table 2: (Maximum Proportion of) Stock Picking in the FTSE350

\begin{tabular}{llllll}
\hline Year & $\mathbf{R}^{2}$ & $\mathbf{( 1 - R}^{\mathbf{2}} \mathbf{)}$ & $\mathbf{F}$-stat & Beta & P-value \\
$1991-2005$ & 69.1 & 30.9 & 505.89 & 1.09 & 0.000 \\
1991 & 53.9 & 46.1 & 158.62 & 1.01 & 0.000 \\
1992 & 52.7 & 47.3 & 165.05 & 1.03 & 0.000 \\
1993 & 60.1 & 39.9 & 234.9 & 1.02 & 0.000 \\
1994 & 61.4 & 38.6 & 256.18 & 1.02 & 0.000 \\
1995 & 59.1 & 40.9 & 236.67 & 1.03 & 0.000 \\
1996 & 64.2 & 35.8 & 298.55 & 1.06 & 0.000 \\
1997 & 67.4 & 32.6 & 372.81 & 1.08 & 0.000 \\
1998 & 67.0 & 33.0 & 393.4 & 1.06 & 0.000 \\
1999 & 72.5 & 27.5 & 525.17 & 1.11 & 0.000 \\
2000 & 78.3 & 21.7 & 737.91 & 1.12 & 0.000 \\
2001 & 78.3 & 21.7 & 764.16 & 1.16 & 0.000 \\
2002 & 82.0 & 18.3 & 953.14 & 1.19 & 0.000 \\
2003 & 81.1 & 18.9 & 895.42 & 1.19 & 0.000 \\
2004 & 79.2 & 20.8 & 789.05 & 1.16 & 0.000 \\
2005 & 79.5 & 20.5 & 807.28 & 1.12 & 0.000 \\
\hline
\end{tabular}

Model: $\operatorname{Ln}(\mathrm{VOL})_{i}=\alpha+\beta_{i} \operatorname{Ln}(\mathrm{NOSH})_{i}+\varepsilon_{i}$

$\mathrm{Vol}=£$ volume of shares traded; $\mathrm{NOSH}=$ number of shares outstanding; measures are mean annual results based on monthly regressions described by the model. 
Figure 1: Stock Picking in the FTSE350 1991-2005.

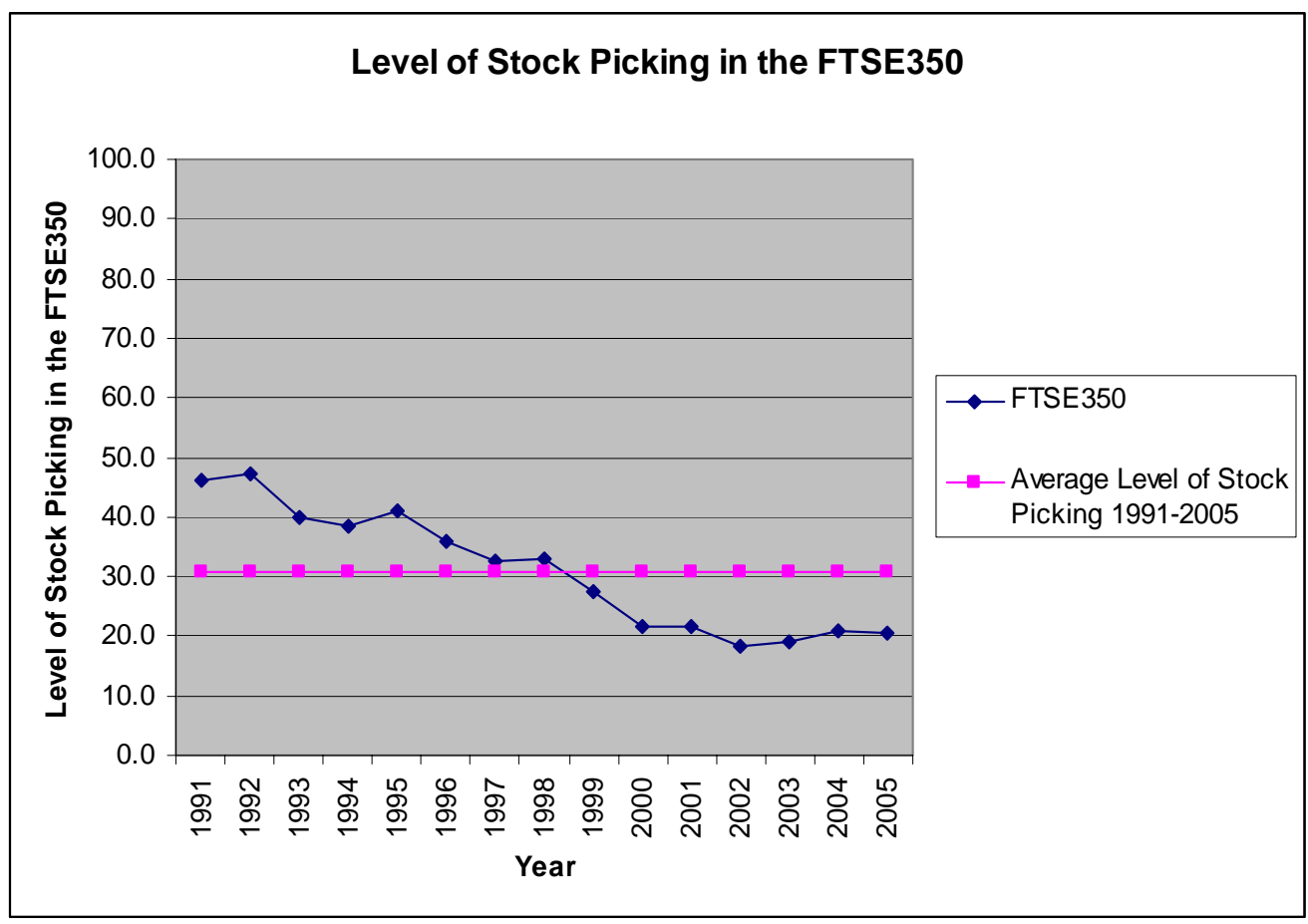


Figure 2: (Maximum Proportion of) Stock Picking in the FTSE350 1991-2005.

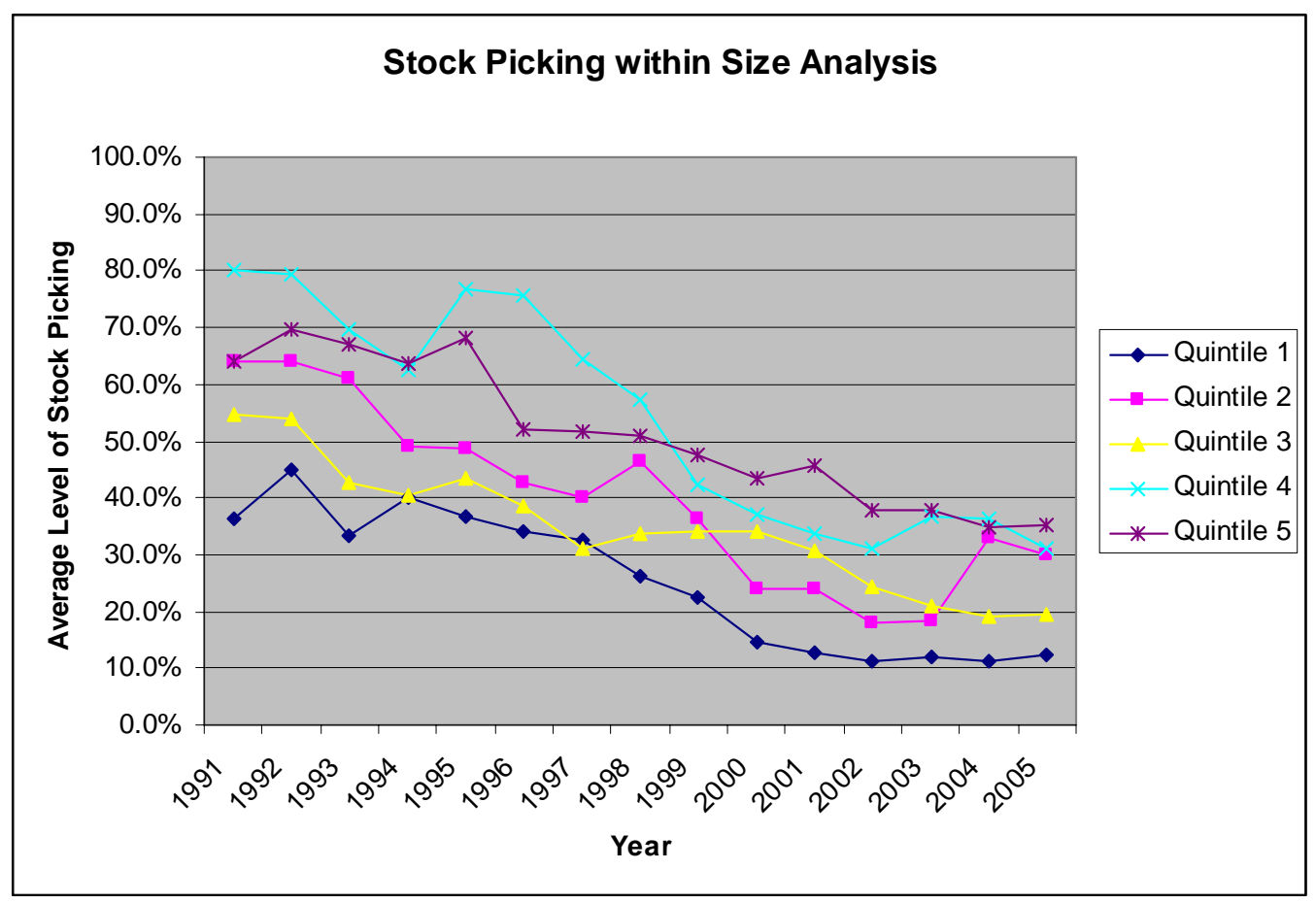


Table 3: (Maximum Proportion of) Stock-Picking in the FTSE350 by Market Capitalisation, 1991-2005.

$\begin{array}{crrrrr}\begin{array}{l}\text { Quintile } \\ (\mathbf{1 9 9 1 - 2 0 0 5 )}\end{array} & \mathbf{R}^{\mathbf{2}} & \left(\mathbf{1 - \mathbf { R } ^ { 2 } )}\right. & \text { F-stat } & \text { Beta } & \text { P-value } \\ 1 & 74.61 & 25.39 & 160.89 & 1.06 & 0.000 \\ 2 & 60.03 & 39.97 & 75.78 & 1.06 & 0.000 \\ 3 & 65.25 & 34.75 & 82.83 & 1.06 & 0.000 \\ 4 & 45.70 & 54.30 & 43.53 & 0.94 & 0.000 \\ 5 & 48.70 & 51.30 & 40.36 & 1.12 & 0.000\end{array}$

Model: $\operatorname{Ln}(V O L)_{i}=\alpha+\beta_{i} \operatorname{Ln}(N O S H)_{i}+\varepsilon_{i}$

$\mathrm{Vol}=£$ volume of shares traded; $\mathrm{NOSH}=$ number of shares outstanding; measures are mean annual results based on monthly regressions described by the model. 
Table 4: (Maximum Proportion of) Stock Picking in the FTSE350 by Industry

\begin{tabular}{|c|c|c|c|c|c|c|}
\hline Industry & $\mathbf{R}^{2}$ & $\left(1-R^{2}\right)$ & Beta & F-stat & P-value & Rank \\
\hline Electrical + Utilities & 29.46 & 70.54 & 0.72 & 734.15 & 0.000 & 1 \\
\hline Real Estate & 44.19 & 55.81 & 1.65 & 284.18 & 0.000 & 2 \\
\hline Equity Investment & 48.88 & 51.12 & 0.74 & 146.41 & 0.000 & 3 \\
\hline Other* & 51.0 & 49.0 & 1.00 & 102.58 & 0.000 & 4 \\
\hline Telecoms & 56.84 & 43.16 & 0.60 & 124.0 & 0.000 & 5 \\
\hline Aero Defence & 57.40 & 42.60 & 0.80 & 68.28 & 0.000 & 6 \\
\hline Computers & 59.63 & 40.37 & 0.82 & 913.31 & 0.000 & 7 \\
\hline Food, Drugs, Retail & 62.32 & 37.68 & 0.95 & 167.34 & 0.000 & 8 \\
\hline Food Producers & 64.32 & 35.69 & 1.30 & 76.67 & 0.000 & 9 \\
\hline Household G+S & 67.56 & 32.44 & 1.31 & 191.87 & 0.000 & 10 \\
\hline Support Services & 69.62 & 30.38 & 1.27 & 350.05 & 0.000 & 11 \\
\hline Engineering, Transport & 72.25 & 27.75 & 0.90 & 133.34 & 0.000 & 12 \\
\hline Travel + Leisure & 77.13 & 22.87 & 1.19 & 238.64 & 0.000 & 13 \\
\hline Insurance & 77.54 & 22.46 & 1.25 & 78.40 & 0.000 & 14 \\
\hline Media & 77.77 & 22.23 & 1.33 & 263.41 & 0.000 & 15 \\
\hline Banks + Gen Finance & 78.02 & 21.98 & 1.18 & 120.43 & 0.000 & 16 \\
\hline Chemical, Pharmaceutical & 83.26 & 16.71 & 0.91 & 205.91 & 0.000 & 17 \\
\hline
\end{tabular}

Model: $\operatorname{Ln}(\mathrm{VOL})_{i}=\alpha+\beta_{i} \operatorname{Ln}(\mathrm{NOSH})_{i}+\varepsilon_{i}$

$\mathrm{Vol}=£$ volume of shares traded; $\mathrm{NOSH}=$ number of shares outstanding; measures are mean annual results based on monthly regressions described by the model. Other* classification includes 40 companies from the following industries; auto and parts, beverages, tobacco, Personnel, $\mathrm{H} / \mathrm{C}$ and Services, Mining, Construction, for which there were fewer than 4 firm-industry observations. 
Table 5: (Maximum Proportion of) Stock Picking in the AIM 1996-2005.

\begin{tabular}{lcccll}
\hline Period & $\mathbf{R}^{\mathbf{2}}$ & $\mathbf{( 1 - R}^{2} \mathbf{)}$ & $\mathbf{F}$-stat & Beta & P-value \\
$1996-2005$ & 23.0 & 77.0 & 164.80 & 0.754 & 0.000 \\
1996 & 1.6 & 98.4 & 10.79 & 0.192 & 0.591 \\
1997 & 24.6 & 75.5 & 38.85 & 0.788 & 0.000 \\
1998 & 20.3 & 79.7 & 47.96 & 0.73 & 0.000 \\
1999 & 24.2 & 75.8 & 79.74 & 0.851 & 0.000 \\
2000 & 16.0 & 84.0 & 76.31 & 0.626 & 0.050 \\
2001 & 16.3 & 83.7 & 90.83 & 0.686 & 0.000 \\
2002 & 17.0 & 83.0 & 87.99 & 0.716 & 0.000 \\
2003 & 25.0 & 75.0 & 135.32 & 0.851 & 0.000 \\
2004 & 39.1 & 60.9 & 233.48 & 1.043 & 0.000 \\
2005 & 45.8 & 54.2 & 292.25 & 1.156 & 0.000 \\
\hline
\end{tabular}

Model: $\operatorname{Ln}(V O L)_{i}=\alpha+\beta_{i} \operatorname{Ln}(N O S H)_{i}+\varepsilon_{i}$

$\mathrm{Vol}=£$ volume of shares traded; NOSH $=$ number of shares outstanding; measures are mean annual results based on monthly regressions described by the model. 
Figure 3: (Maximum Proportion of) Stock-Picking in the FTSE350, AIM for the period 1996-2005 inclusive.

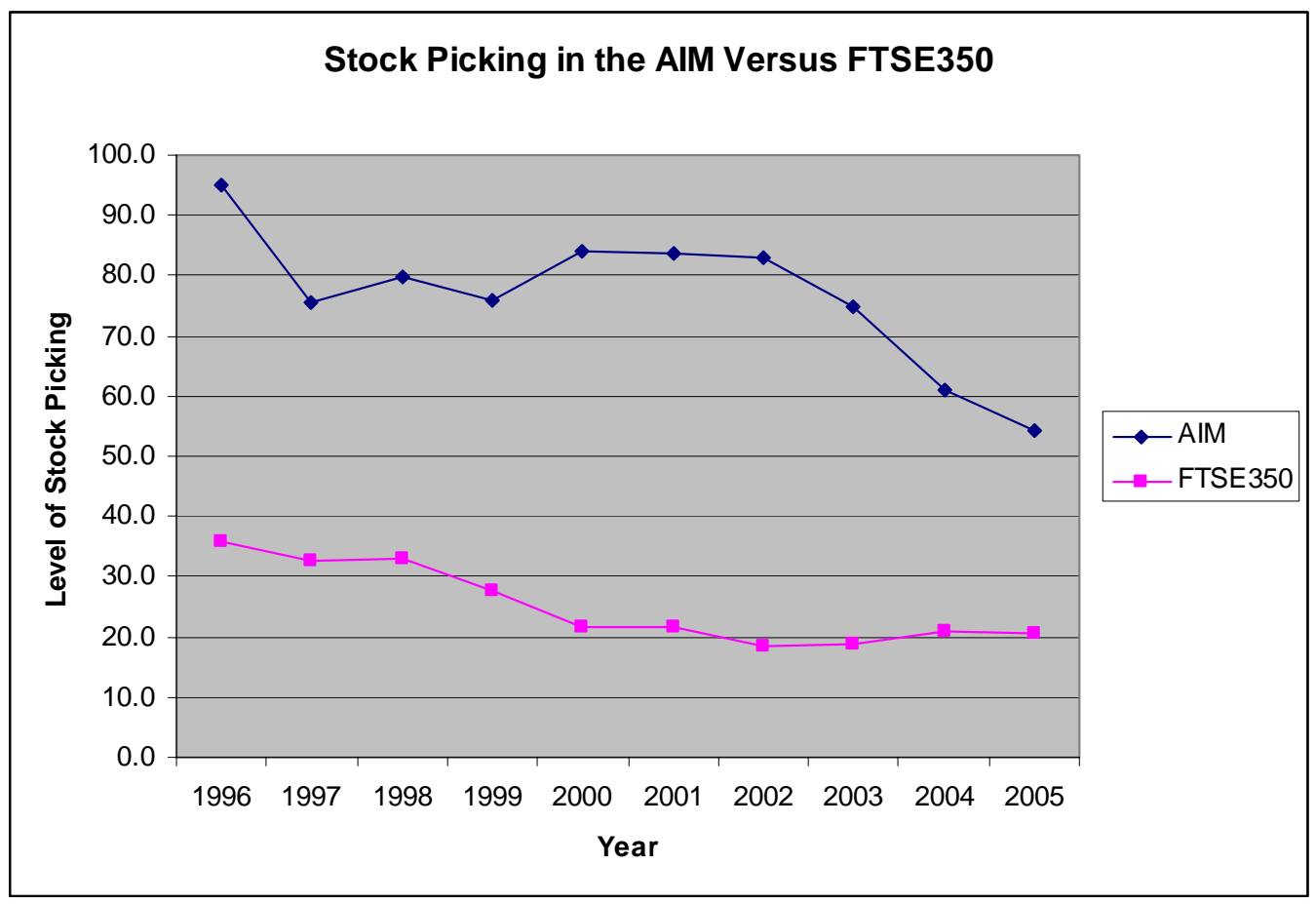




\section{REFERENCES}

Bhattacharya, U and Galpin, N. (2005). "Is Stock Picking Declining Around the World?" AFA 2007 Chicago Meetings Paper, available at SSRN: http://ssrn.com/abstract $=849627$

Carhart, M. (1997). "On Persistence of Mutual Funds." The Journal of Finance, Vol. 52, No. 1, 57-82.

Economist. (2006) "Passive Aggression; Americas Shareholders Settle for Guaranteed Mediocrity:" January, 76, and "Alpha Betting", September $16^{\text {th }}, 85$.

Fama, E and French, K. (1996). "Multifactor explanations of asset pricing anomalies." Journal of Finance Vol. 51, 55-84.

Grinblatt, M. and Titman, S. (1989). "Mutual Fund Performance: An analysis of quarterly portfolio holdings." Journal of Business, Vol. 62, 394-415.

Grinblatt, M. and Titman, S. (1993). "Performance measurement without benchmarks: An examination of mutual fund returns." Journal of Business, Vol. 66, 1977-1984.

Grossman, S. and Stiglitz, J. (1980). "On the Impossibility of Informationally Efficient Markets.” The American Economic Review, Vol. 70, No. 3, 393-408.

Gruber, M. (1996). "Another Puzzle: The Growth in Actively Managed Mutual Funds." The Journal of Finance, Vol. 51, No.3, 783-810.

Jensen, M. (1968). "The Performance of Mutual Funds in the Period 1945-1964." The Journal of Finance, Vol. 23, No. 2, 389-416.

Karpoff, J.M. (1987). "The Relation between Price Changes and Trading Volume: A Survey”. Journal of Financial and Quantitative Analysis Vol. 22, No. 1, 109-126.

Lintner, J. (1965). "Security Prices, Risk and maximal Gains from Diversification." Journal of Finance, XIX, 587-616.

Lo, A. and Wang, J. (2000). "Trading Volume: Definitions, Data Analysis, and Implications of Portfolio Theory." The Review of Financial Studies, Vol. 13, No. 2, 257-300.

Malkiel, B.G. (2003). “The Efficient Markets Hypothesis and its Critics”. European Financial Management, Vol. 9, No. 1, 1-10.

Markowitz, H. (1952). "Portfolio Selection.” The Journal of Finance, Vol. 7, No. 1, 77-91.

Sharpe, W. (1964). "Capital Asset Prices: A Theory of Market Equilibrium Under Conditions of Risk" Journal of Finance, XIX, 425-442. 
Tobin, J. (1958). 'Liquidity preference as behaviour towards risk. Review of Economic Studies 25, 65-86.

Wermers, R. (2000). "Mutual fund Performance: An Empirical Decomposition into Stock-Picking Talent, Style, Transaction Costs and Expenses." Journal of Finance Vol. 55, No.4, 1655-1695. 